\title{
Cloud computing for a dynamic and synchromodal container consolidation
}

\author{
A. Tsertou ${ }^{1}$, A. Amditis ${ }^{1}$, T. Theodoropoulos ${ }^{1}$, E. Latsa $^{2}$, \\ J. Kanellopoulos ${ }^{3} \&$ M. Kotras ${ }^{3}$ \\ ${ }^{I}$ I-SENSE Group, Institute of Communication and \\ Computer Systems, Greece \\ ${ }^{2}$ SEAbility Ltd, Greece \\ ${ }^{3}$ Piraeus Container Terminal, Greece
}

\begin{abstract}
Since the container became the driver of change in worldwide freight transport, the optimal utilization of container capacities has become a key challenge of the supply chain management. Often, fragments of customer orders arrive at their destination via different, sub-optimal routes which impose increased delivery times, costs and $\mathrm{CO}_{2}$ emissions to the global supply chain. A barrier to efficient container consolidation at port terminals is the reduced visibility and limited information exchange between stakeholders on real-time location and status of a container and its contents. This is due to a multitude of reasons: the lack of a common standard for information exchange, competition matters, absence of trusted service providers collecting data, information shared on a next carrier basis without disseminating information to the rest of the stakeholders. In addition, multimodal transport involves many carriers until the goods reach their final destination. Well-defined trigger points regarding cargo will allow for better monitoring of shipments and the introduction of KPIs for route evaluation and carrier performance. This work proposes a cloud-based information portal as an ICT enabling technology used by supply chain stakeholders; the latter will use this portal to feed it with real-time information from existing platforms so that a better visibility for all parties is enabled. This portal will permit better visibility for end-customers, promote standardization of logistics processes, offer an increased profitability for cloud services providers, improve their activities expansion and accelerate customs related process handling.

Keywords: container consolidation, dynamic, synchromodality, cloud computing, portal, PaaS.
\end{abstract}




\section{Introduction}

Worldwide traditional manufacturing models and processes have started to radically change in the recent years. Incentivised and supported by the latest advances in additive manufacturing, online ICT (Information and communication technologies) collaborative tools, e.g. IoT (Internet of Things), cloud services, SaaS and Paas (Software and Platform as a Service) architectures and lately 3D printing, today's industry giants as well as startup companies are increasingly incorporating the model of customized and distributed manufacturing. Supply chains are redefined due to a combination of specialized additive manufacturing technologies, open source advances and online collaboration. Within this framework, the challenge of optimised container consolidation in large maritime transport hubs becomes more and more relevant but at the same time complex to address.

A significant barrier to an efficient container consolidation at container terminals is the reduced visibility and limited information exchange between all related stakeholders, i.e. shippers, carriers, warehouse management systems, forwarders and container terminal operators on real-time location and status of a container and its contents. This is due to a multitude of reasons: the lack of a common standard for information exchange, competition matters, absence of trusted service providers collecting data, information shared on a next carrier basis without disseminating information to the rest of the stakeholders. For instance, shipments are usually monitored at order level and unit quantity. This information is practically useless to warehouses since it is almost impossible to track packaging dimensions of every single product passing through the warehouse. If number and type of pallets used per order was available in advance, then planning and consolidation of shipments would have been easier and faster. This information is available at the manufacturing site but rarely passed on to the carriers. Moreover, multimodal transport involves a number of carriers till the goods reach their final destination. Well-defined trigger points on standard routes may be reported by the carriers, i.e. arrival of goods, shipment of goods, start of processing, duel times, credit releases, customs authority releases etc. and will allow for better monitoring of shipments and introduction of KPIs (Key Performance Indicators) for route evaluation and carrier performance.

This paper describes the objectives, features and benefits for a cloud-based information portal which will be used as a single point of reference by relevant supply chain stakeholders; the latter will use this portal to feed it with real-time information from existing systems/platforms so that a better visibility for all parties is enabled. This portal should implement accessible interfaces with parties of each step of the transport process, e.g. interface with the customer, warehouse, next-leg carrier etc. using harmonized/standardized formats as far as possible, e.g. EDI (Electronic Data Interchange) gateways, SSM (Shipment Status Message) gateways. It will also allow for a flexible and seamless parameterization per customer/end-user as well as for a straightforward incorporation of regional/local special requirements, as is the constraint of single customer per container applicable in some LEVANT countries. This portal will 
permit a better level of visibility for end-customers, promote standardization of logistics processes, offer an increased profitability for data/cloud services providers and improve their activities expansion, as well as accelerate customs related process handling.

\section{Literature review}

For a fully functional container terminal to be able to operate efficiently and accommodate intermodal and synchromodal traffic, a broad set of different ICT software and platforms are necessary to support and monitor related activities. These can be generally categorized in the following clusters according to the classification in Perego et al. [1]:

- Transport Management (TM) tools: Decision support tools in transportation planning and optimisation, with typical functionalities including carrier load tendering, routing and scheduling, shipment tracking and tracing, and freight payment and auditing $[2,3]$. Track-and-trace systems are becoming more and more popular for freight transport, in most of the cases provided only as informative tools; sometimes, however they are also accompanied by modules performing route optimization using complex algorithms from predictive analytics or machine learning domains.

- Supply chain execution (SCE) tools: Tools designed to manage and automate information exchange and real-time management during the actual execution of a distribution schedule according to Giaglis et al. [4]. In this category belong classic tools for warehouse management, i.e. Warehouse Management Systems (WMS) as well as Enterprise Resource Planning systems (ERP). Even more importantly, the Terminal Operating Systems (TOS) may be classified under this category and are tools of primary importance to the supply chain, controlling the movement and storage of cargo/containers in and around a container terminal or port.

- Fleet and freight management (FFM) tools: Tools providing vehicle travel times, service times, delivery points visited and other parameters, e.g. load temperature, as real-time input to dynamic vehicle management functions so that a fleet of vehicles may be efficiently managed. Vehicle tracking devices with positioning capabilities such as Global Navigation Satellite Systems (GNSS) fall under this category, as well as the increasingly popular Container Security Devices (CSD) explained in a Worldbank report [5].

- Field force automation (FFA) tools: Tools enabled by mobile technology and supporting the integration between remote workforce and corporate business processes [6].

The vast majority of the aforementioned solutions are targeting to solve specific operational and optimisation issues. Nevertheless, they are mainly 
proprietary, tailored for the needs of specific stakeholders of the logistics chain and are incapable of solving a global issue as is the container consolidation that requires interoperability and information sharing among various and diverse members of the supply chain around a container terminal. In order to bridge this gap, a number of solutions have been proposed recently in order to facilitate integration among the aforementioned tools and corresponding stakeholders. The scope of the following review of such tools has mainly a container port as the epicentre; specialized integration tools referring to other means of transport hubs, such as airports or large distribution centres are beyond the scope of this paper.

- Port Community Systems: According to the definition of the International Port Community Systems Association IPCSA [7], "PCS is an electronic platform that connects the multiple systems operated by a variety of organisations that make up a seaport or airport community. It is shared in the sense that it is set up, organised and used by firms in the same sector - in this case, a port community." PCS are key enablers for the transition of ports all over the world and their countries towards the Single Window environment; they are usually modular systems facilitating interactions among players within a port community regarding exports, imports, transshipments, dangerous goods and consolidations. Most of them allow for an EDI-based information exchange, customs declarations, electronic handling of information regarding import and export, tracking and tracing across the supply chain.

- Supply Chain Control Towers: A supply chain control tower is a central hub with the technology to use supply chain data to provide enhanced visibility for decision-making aligned with strategic objectives. The control towers have been enabled by cloud-based technology and accommodate a broad set of services collecting and aggregating orders, shipments, inventory and status. They take advantage of order and transportation management software applications and facilitate data exchange between carriers, logistics service providers and senders and receivers of goods and have been successfully adopted by many ICT companies in the field of logistics [8, 9]. They may be implemented in different architectures, e.g. at centralised locations for many customers in a shared environment or dedicated on-site or remote for a single customer.

In recent years, a number of publications have advanced the use of cloud computing in logistics processes. Nevertheless, this has not been examined nor applied to port terminal operations such as the container consolidation. In particular, Schuldt et al. [10] identified the potential of cloud computing to facilitate autonomous control in logistics and allow for scaling autonomous logistics applications based on dynamically arising logistics demands. A fourlayer architecture is suggested: 
- Infrastructure as a Service (IaaS) option, where the logistics users may use a scalable hardware platform from the cloud service provider to install their own logistics ICT tools;

- PaaS option, where a software platform is provided which offers a given set of services, usually in an agent-based implementation; the cloud service provider is the administrator of the software platform;

- SaaS option, where a complete implementation of software agents for autonomous control in logistics is provided; the user delivers only process information;

- Process as a Service option, which does not only provide a software implementation for autonomous logistics but also a platform that integrates logistics service providers that execute the services demanded.

Moreover, Holtkamp et al. [11] introduced the "Logistics Mall platform" with the aim of providing a market place for logistics services and processes together with a cloud based access and execution environment. The Logistics Mall consists of two components: mall marketplace and customized access framework: the former is a specialised web shop for logistics IT services and logistics process support, whereas the latter implements a logistics specific SaaS layer and provides a customer company of the Logistics Mall with a user specific framework for access to multiple logistics applications and is designed for public use.

\section{Features and benefits of cloud computing for container consolidation in a port terminal}

In a modern container terminal, such as the Piraeus Container Terminal (PCT, a wholly-owned subsidiary of COSCO), innovative ICT tools are considered a vital factor for the port development. In fact, the terminal uses a number of different ICT tools and platforms in order to perform the operations, security and management of terminal as well as support its interfaces with other transport modes such as rail- or truck-based transport. These tools include: (i) a Terminal Operating System (TOS) with a full suite of planning, operation and management system modules covering the total operations of the terminal and utilizing terminal resources fully; (ii) an Optical Character Recognition (OCR) portal where only the trucks that have an active job according to the TOS are allowed to proceed to the terminal entrance and which is used by the trucking companies to manage container jobs and assign them to Driver IDs; (iii) a realtime web services platform, where the following services are offered: information about the short \& long term vessel schedule, information on the progress of works on working vessels, gate information, scheduled or stacking container information, real-time information for container discharge to custom 


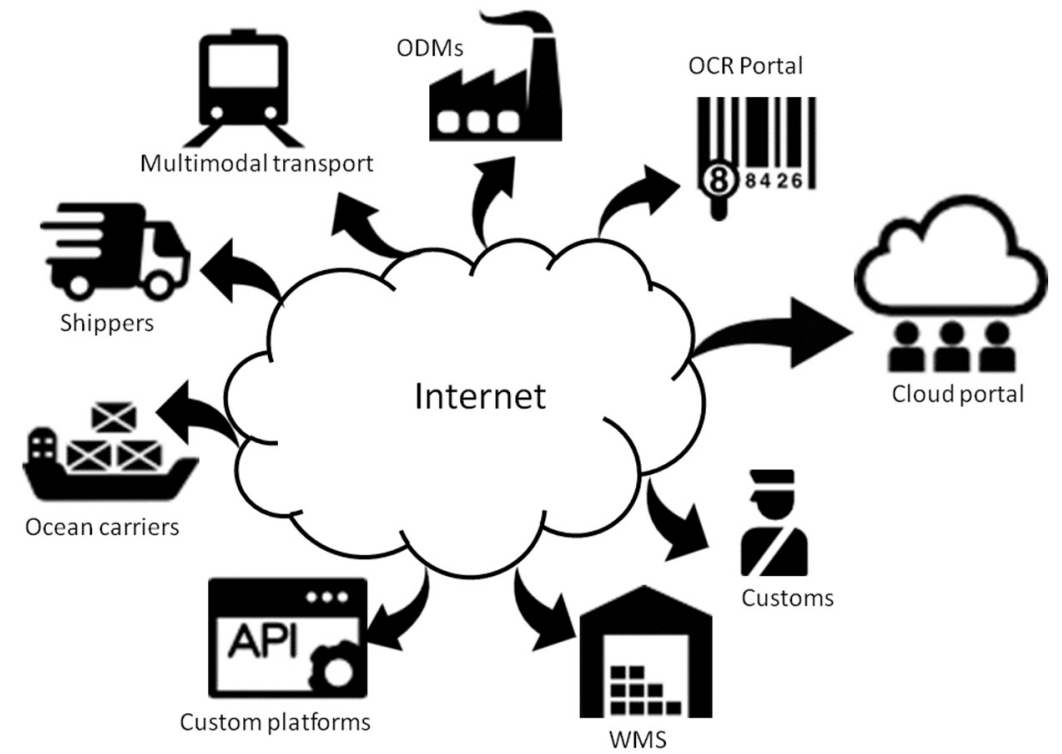

Figure 1: The cloud portal integrates different data sources and platforms.

brokers, yard statistics; (iv) a custom-made planning platform for cargo, where the status of shipment for its major ODM clients may be tracked, it has an internal registry for Shipment Status Messages (SSMs), designating important trigger points to be reported i.e. arrival of container in the terminal, shipment of container, start of processing in the container terminal, credit releases, customs authority releases and also has an active interface to the Warehouse Management System of the distribution centre located in the close proximity of the container terminal.

For all the aforementioned tools and platforms, it is not straightforward and cost-effective to maintain the related network and storage infrastructure. In fact, due to a rapid increase in the terminal's TEU traffic in the recent years, the complexity of maintaining a hardware architecture sufficient to host these tools has become difficult to sustain. Moreover, these tools are not capable to cope with an efficient container consolidation process at least not in a holistic way that does not depend on separate proprietary solutions per single customer. This fact has rendered legacy solutions - even the ones supporting integration activities, as are the PCS - incapable to support the resulting exponential growth in hardware infrastructure and sustainability requirements and to this end, a cloud based information portal is currently planned (see fig. 1). This portal will gradually replace the current in-situ infrastructure and it will meet the scalability and efficiency requirements of a multi- and synchromodal container terminal as is PCT.

In this cloud based architecture, the maintenance of the respective infrastructure may be hosted by a third party through a Service Level Agreement. More importantly, at the same time, collaborating external companies and 
organizations may use a subset of this pool of resources and services, according to access rights determined by the container terminal. This will be enabled by the concept of 'Information Profiles'. This concept is an extension of the notion of 'Logistic Service Profile' introduced in [12] which contains a semantically supported description for each of the layers of the ontology proposed. In particular, the Information Profiles specify resource characteristics in terms of the type of data they share, both semantically and syntactically, metadata, etc.; an Information Profile is the basis to search and find resources for all interconnected members of the container terminal-centric supply chain. Through automatic transformation, the cloud portal will be able to transparently integrate totally diverse services; from logistics services, as is the management of credit holds/releases to traffic management services, as is the notification in a motorway traffic management centre of the entrance of a truck fleet carrying e.g. dangerous cargo.

The aforementioned features allow that external stakeholders are only accessing - on a demand-driven basis - sharable information granted by the terminal. This is very important for many small and medium enterprises, such as shipping companies, that are collaborating with the container terminal and will thus be freed from the burden of managing the complexities of ICT applications. This pay-per-use feature also means that scaling down or up according to fluctuations in cargo traffic conditions does not cost the terminal or the shipping companies a fortune or require a significant investment. On the other hand, this architecture is able to accommodate the substantial amount of data from a multitude of end devices (e.g. track and trace systems, On Board Units, Road Side Units, legacy or IoT devices) which are necessary to keep up-to-date information of container and cargo status from and to all parties. It also has the capacity to accommodate data stemming from social media networking applications which are now in the forefront of logistics state of the art; truck drivers tend to use social media to provide updates on traffic status in an ever increasing rate [13].

The traditional method of communication between shippers and carriers for containers passing through the container terminal is bilateral and partially fragmented. In essence, the terminal would publish targeted SSM messages to corresponding stakeholders through the aforementioned custom-made planning platform through a hub and spoke fashion. In fact, during the last five years, the Piraeus Container Terminal has become a container consolidation centre for the Southern Eastern Mediterranean region and beyond with a consequent exponential increase of multimodal traffic; thus, the network of next legs of each container journey through air, rail and truck has significantly expanded and so have the number of associated shippers and freight forwarders. This has a direct effect in the complexity of maintaining separate interfaces with all such organizations that, besides, have a different level of ICT automation; these interfaces are becoming increasingly challenging and ineffective for the container terminal to maintain. Through a cloud based portal, during all phases of goods being in transit, all concerned stakeholders are constantly updated by the portal on the status of each shipment. This includes palette information, 
which is fundamental for an efficient container consolidation at the terminal. If number and type of pallets used per order was available in advance, then planning and consolidation of shipments would have been easier and faster. This information was till now available at the carrier but rarely made it to the freight forwarders.

This increased visibility enables the terminal as well as its collaborating organisations to be in greater control of the consolidation process and more importantly to be proactive in responding to exceptional events. The portal will also facilitate financial settlements and feedback/performance reviews. In this manner, all modes of transport connected with the container terminal (ocean traffic, air, rail and truck) may operate into an interconnected streamlined supply chain with the terminal as the epicentre. Associated benefits include a significant cost reduction and an increased customer service improvement, resulting to a win-win situation for all parties. Another benefit of the cloud information portal adoption is its simplicity to manage and administer all previously described ICT devices, tools and platforms deployed, as the terminal and its stakeholders may rely more on the service provider (third party) instead of putting significant efforts on the internal IT department. This solution will also provide to the terminal the ability to add and remove computing capacity on demand; this ability is crucial and very effective for the process of dynamic container consolidation, which naturally exhibits a great variance depending on time of day, season or after unexpected weather conditions. Only referring to two such examples, traffic seems to escalate on Fridays whereas it is much lighter during other weekdays, while it also seems to have peaks once bad weather causes the Suez Canal to close for a few hours.

\section{Challenges and discussion}

However, there are still several challenges to address and account for -both in a technological as well as in a trust/governance level, despite the important benefits from the adoption of a cloud-computing based solution which were mentioned above.

One major concern and challenge is security and reliability. As every respectable company, the container terminal has a necessity to protect cargo, information about the cargo and its associated customers. Lost data can lead to lost carriers, lost shipping companies and ultimately lost TEU traffic. So security is a prime concern. The responsibility for the reliability and security of cloud infrastructure lies mainly with the technology service provider; issues still are challenging to solve and the trust level of stakeholders needs to increase. Due to the security and privacy issues, the followed architecture is hybrid: it is a mixture of public and private cloud structure, in which critical for the container terminal activities are performed using private cloud and are only accessible from within the organization and thus more secured, while the non-critical activities are performed using the public or community-level cloud, allowing access to the container terminal's external stakeholders, i.e. shipping companies, the customs authorities, AIS etc. 
Another issue is collaboration among stakeholders involved: as is the case with most of supply chain actors, it is not easy or even feasible to own or operate the associated entire supply chain from end-to-end. Therefore, decisions about using (and ways of using) cloud technology may involve multiple partners, often creating complexities or even obstacles between associated organizations. Moreover, innovation cannot move faster than the customer. Regardless of the extensive benefits the cloud computing portal could bring to associated shipping companies, it is a new technology that is not yet accepted and understood by everyone. It is possible that several collaborating shipping companies will show lack of trust and poor support due to scepticism and lack of understanding of the new technology and the benefits it might deliver.

Summarising, this paper has explained the motivation behind the adoption of cloud technology for the needs of a modern container terminal as opposed to traditional ICT platforms and systems. The main arguments for the use of cloud services were discussed and the main benefits for the terminal itself as well as for the entire supply chain were presented. Finally, current obstacles which this technology still needs to face were outlined, with security, reliability and stakeholders' trust being the most important ones.

\section{Acknowledgement}

The graphics in Figure 1 were designed by Freepik.

\section{References}

[1] Perego, A., Perotti, S. and Mangiaracina R., 2011. "ICT for logistics and freight transportation: a literature review and research agenda", International Journal of Physical Distribution \& Logistics Management 41.5, 457-483.

[2] Gilmore, D. and Tompkins, J., 2000. "Transport plays key role in supply strategy". ID Systems, Vol. 20, pp. 16-17.

[3] Tyan, J.C., Wang, F.K. and Du, T., 2003. "Applying collaborative transportation management models in global third-party logistics". International Journal of Computer Integrated Manufacturing, Vol. 16 No. 4, pp. 283-291.

[4] Giaglis, G.M., Minis, I., Tatarakis, A. and Zeimpekis, V., 2004.” Minimizing logistics risk through real-time vehicle routing and mobile technologies". International Journal of Physical Distribution \& Logistics Management, Vol. 34 No. 9, pp. 749-764.

[5] Worldbank Resources, 2015. "SCS Technologies for Container Integrity: Container security devices and seals". http://siteresources.worldbank.org/ INTTRANSPORT/Resources/336291-1239112757744/59976931252703593834/6433604-1256564181444/6505010-1256582144983/ seals.pdf, Webpage accessed 20/9/2015.

[6] Rodina, E., Zeimpekis, V. and Fouskas, K., 2003. "Remote workforce business processes integration through real-time mobile communications". 
Proceedings of 2nd International Conference on Mobile Businesses, Vienna.

[7] International Port Community Systems Association IPCSA, Port Community Systems, 2014. http://www.epcsa.eu/pcs, Webpage accessed $16 / 12 / 2015$.

[8] CEVA Press Release 2011, “CEVA's Control Tower recognized for excellence at Smau 2011", http://www.cevalogistics.com/release/25-Oct2011, Webpage accessed 16/12/2015.

[9] Kuehne+Nagel, 2015. "Logistics Control Tower", http:/www.knportal.com/integrated_logistics/logistics_control_tower/ Webpage accessed 22/9/2015.

[10] Schuldt, A., Hribernik, K., Gehrke, J.D., Thoben, K.D. and Herzog, O., 2010. "Cloud Computing for Autonomous Control in Logistics". GI Jahrestagung (1), pp. 305-310.

[11] Holtkamp, B., Steinbuss, S., Gsell, H., Loeffeler, T. and Springer, U., 2010. "Towards a logistics cloud". Sixth IEEE International Conference on Semantics Knowledge and Grid (SKG), pp. 305-308.

[12] Hofman W., 2012. "iCargo:Semantic Interoperability in Logistics Supply Chains". 5th European Conference on ICT for Logistics ECITL, Gothenburg, Sweden.

[13] Telogis Blog, 2015. "How are fleet managers using social media", http://www.telogis.com/blog/fleet-managers-using-social-media/ Webpage accessed 20/12/2015. 